\title{
El turista 2.0 como receptor de la promoción turística: estrategias lingüísticas e importancia de su estudio ${ }^{1}$
}

\author{
Francisca Suau Jiménez \\ Universitat de València (España)
}

\begin{abstract}
Resumen: El turista/viajero es cada vez más quien gestiona sus viajes a través de Internet. El término turista 2.0, denomina a este nuevo agente. Por ello, las webs turísticas han de tener en cuenta ciertos mecanismos y estrategias lingüísticas y visuales que cumplan el objetivo de los géneros de promoción: la persuasión. Estas estrategias lingüísticas se construyen mediante funciones retóricas como la descripción, la ejemplificación, la sugerencia, etc., así como la interpersonalidad, función discursiva que designa la relación entre emisor y receptor del texto a través de marcadores, sujeta a variaciones lingüísticas y culturales y que modaliza la persuasión. Será, pues, necesario el análisis de estas estrategias y sus diferencias interlingüísticas para incorporarlas de forma sistemática a dichas webs de promoción turística.
\end{abstract}

Palabras clave: turista 2.0, interpersonalidad, funciones retóricas, estrategias lingüísticas, marcadores, persuasión

Title: The 2.0 tourist as recipient of touristic promotion: linguistic strategies and importance of its study

\begin{abstract}
The traveller/tourist is the one who increasingly manages her/his trips through the Internet. A new term, that of tourist 2.0, defines this new agent. Therefore, specific linguistic and visual mechanisms and strategies have to be applied when constructing these promotional web sites so as to assist their generic persuasive aim. These linguistic strategies are realized through rhetorical functions such as description, exemplification, suggestion, etc. and of interpersonality, the discursive interactional function that designates the relation between text sender and receiver through specific markers that vary cross-linguistically and modulate persuasion. It is then necessary to identify and analyze these strategies and their cross-linguistic differences in order to incorporate them systematically into touristic promotion web sites.
\end{abstract}

Keywords: tourist 2.0, rhetorical functions, interpersonality / interactional function, linguistic strategies, markers, persuasion 


\section{Introducción}

La intención del presente estudio es reflexionar sobre las estrategias lingüísticas que constituyen el discurso de promoción turística, especialmente en los géneros institucionales de páginas web. El interés por este campo de las estrategias lingüísticas del discurso del turismo radica sin duda en las diferencias inter-lingüisticas existentes, producidas por el sustrato socio-cultural que cada lengua, en este caso el inglés y el español, tienen. Estas diferencias se han de tener en cuenta tanto al redactar como al traducir géneros de promoción. Las estrategias lingüísticas se materializan principalmente a través de una variedad de funciones retóricas como la descripción, la ejemplificación, la sugerencia de actuación, etc. y a través de la función interpersonal, que es globalizadora ya que está entretejida en la totalidad del texto. La función interpersonal designa la relación entre emisor y receptor y es fundamental para la consecución del objetivo comunicativo de los géneros de promoción turística, la persuasión del lector. Tanto las funciones retóricas como la función interpersonal tienen una realización diferenciada en cada lengua, por lo que el análisis de ambas áreas en inglés y español es necesaria, con objeto de extraer unos patrones descriptivos y prescriptivos que ayuden a conocer en profundidad dichas estrategias y a aplicarlas en la creación, redacción y - si es necesario - traducción de las webs de promoción turística. Para ello nos hemos basado en investigaciones anteriores que hemos utilizado como referentes y en ejemplos ad hoc que hemos analizado, extrayendo conclusiones que pueden ayudar a conocer mejor la promoción turística y sus entresijos lingüísticos.

La correcta redacción y traducción de webs de promoción turística es hoy en día más importante que nunca si cabe, ya que es el propio turista o viajero quien, cada vez más, busca, compara, decide y compra directamente sus propios viajes y destinos turísticos a través de la red. Por lo tanto, ya no son los intermediarios o agencias de viajes quienes han de convencer al viajero sino los propios sitios web, que han de incluir todo un entramado de estrategias lingüísticas necesarias para este fin. Por ello es importante que se hagan estudios y análisis discursivos de forma contrastiva, tanto en español como en otras lenguas de uso en el campo del turismo. Éste es, pues, el objetivo del presente trabajo.

\section{El turista/viajero 2.0 y el discurso del turismo}

Desde hace un tiempo a esta parte, el turista/viajero se concibe cada vez más como alguien que gestiona sus viajes directamente por Internet. Según el diario El País, sección CiberP@ís, del 29/10/2010, uno de cada tres viajeros compra sus viajes online y el $96 \%$ de quienes viajaron en 2009 consultó Internet antes de hacerlo. Citando este mismo artículo, "la tecnología se ha colado en nuestra forma de viajar desde que pensamos en irnos de vacaciones hasta que regresamos a casa". Así se ha acuñado el nuevo término de turista 2.0, un viajero más informado que nun- ca, participativo, que busca y compara y que ya no decide a partir del consejo de una agencia de viajes, sino que ha de ser persuadido directamente por el producto o servicio turístico y la forma en que éste se presenta en Internet. De ahí la importancia del diseño de páginas web de turismo, tanto en lo que se refiere a imágenes como a texto, con una perspectiva multimodal.

El discurso del turismo forma parte de las llamadas lenguas de especialidad, caracterizadas por ser el producto de la actividad comunicativa de una comunidad discursiva concreta (Swales, 1990; Alcaraz Varó, 2000). Podríamos decir también, siguiendo a Pickett (1989), que el lenguaje del turismo es un ergolecto o lenguaje de trabajo, caracterizado por tener unas funciones comunicativas 0 retóricas y unos conceptos propios, todo lo cual le confiere una identidad estructural y léxico-semántica que lo diferencia de otras lenguas de especialidad (Suau Jiménez, 2001). Estas funciones retóricas y conceptos se expresan tanto a través de un léxico general y específico como de unas estructuras verbales recurrentes o funciones que responden a las transacciones típicas de la actividad de esta comunidad discursiva (Swales, 1990). Estas transacciones podrían denominarse macro-destrezas, dentro de las cuales se dan, de modo reiterativo, un número de funciones comunicativas o retóricas que es necesario aislar y analizar para conocer cómo se comporta este discurso en particular.

La importancia socioeconómica del turismo junto con la falta de definición de la lengua turística de especialidad ha contribuido a que ésta se haya considerado parte del discurso de los negocios (Brieger, 1997; Alesón Carbonell, 2000; Cerdá Redondo, 2000). Sin embargo, y a raíz de haberse publicado diversos diccionarios de turismo, se empezó a comprobar que existen diferentes campos semánticos (alojamiento, arte, cultura, clima, deportes, espectáculos, gestión, seguros, viaje, paisaje) que indican que el lenguaje del turismo posee características propias y singulares (Collin, 1994; Alcaraz Varó et al., 2000). Calvi (2010), en su exhaustivo estudio sobre el discurso de los géneros turísticos, habla de la heterogeneidad de los mismos y del enfoque de acercamiento al público:

Mientras que en el área de la gestión se emplean formas discursivas parecidas a las de otras actividades comerciales, la comunidad de los expertos del viaje elabora un lenguaje original cuando se dirige al público, para atraerlo, informarlo y dirigir su mirada, ejerciendo un significativo impacto social (2010: 19).

Igualmente, Calvi menciona la irrupción de la comunicación a través de la Red, lo cual ha supuesto la recontextualización de esta comunicación, "rompiendo con las convenciones y creando nuevos horizontes de espera en los destinatarios" (2010: 20). En toda esta comunicación, sobresale especialmente el enfoque promocional, por ejemplo, en páginas web, favoreciendo así el uso de formas ponderativas - especialmente a través de realzadores adjetivales y otros marcadores adverbiales - que alaban las 
características de destinos, itinerarios, rutas y alojamientos diversos, con objeto de captar la atención e interés del turista/viajero (Mapelli, 2008; Suau Jiménez, 2011b).

\section{La promoción turística y la comunicación escrita}

La promoción turística es, pues, dentro del lenguaje del turismo, una herramienta indispensable para dar a conocer los servicios y productos que se quieren ofrecer al potencial turista/viajero 2.0, es decir, para comunicar y persuadir.

Dentro de la comunicación turística podemos distinguir dos modalidades clave: la comunicación profesional entre distintos expertos del sector y la comunicación entre profesionales y usuarios, que se desarrolla tanto de forma directa, basada en interacciones orales (conversaciones en agencias de viaje, hoteles, etc.) como indirecta, basada en interacciones diversas escritas (guías, folletos, prensa especializada, anuncios publicitarios, páginas web). Esta última opción, la web de promoción, es una de las que más auge tiene últimamente, hasta el punto de que hay un nuevo concepto de turista, el turista 2.0, como hemos indicado antes, que es a quien van dirigidas, ya que el incremento de ventas turísticas por Internet y de forma directa al cliente es espectacular, y sigue creciendo.

En la esencia misma del discurso turístico está implícita, por lo tanto, la figura del receptor, a menudo equiparable a cliente, con lo cual la función persuasiva es una de las más habituales en los textos turísticos. Por tanto, además del estudio de los géneros de promoción y su estructura discursiva, la relación interpersonal entre el emisor y el receptor del texto es aquí fundamental, así como su expresión textual (Mapelli, 2007; Suau Jiménez y Dolón Herrero, 2007).

La comunicación escrita en el ámbito turístico tiene que integrar todas aquellas estrategias lingüísticas que se adecúen al objetivo último de los distintos géneros que se han identificado como característicos de este campo (Calvi, 2010). Según lo dicho anteriormente, destacan poderosamente los géneros a través de Internet: foros de viajeros, blogs o páginas web promocionales, en todos los cuales el turista 2.0 tiene un papel activo y receptivo particular.

\section{Estrategias lingüísticas que forman el discurso tu- rístico promocional}

En nuestro caso, nos vamos a centrar en las estrategias lingüísticas dirigidas a persuadir al lector, aquí viajero/turista 2.0. La composición de estas estrategias es dual, estando por una parte formada por funciones retóricas específicas de los géneros turísticos de promoción como webs de hoteles, de destinos, etc. Las principales serían la descripción, la ejemplificación, la explicación, la sugerencia, la indicación y la recomendación.Todas ellas forman el contenido proposicional de un texto, es decir, el de mayor carga léxico-semántica, el cuerpo del texto, necesario para construir el género. Su importancia radica en el hecho de que estas funciones se encuentran en los géneros promocionales más prototípicos del ámbito turístico (webs y folletos impresos, tanto institucionales como privados), y son esenciales para la identificación de estos y para su uso comunicativo por la comunidad de habla del turismo (Swales, 1990; Suau Jiménez, 2001b; Calvi, 2010). Su objetivo comunicativo es la persuasión. Estas funciones son similares en cuanto a sus tipos, se trate de una lengua o de otra, ya que los géneros turísticos tienen homogeneidad en su composición o estructura genérica, al menos en lo respecta a los estudios realizados hasta la fecha. Lo que cambia es la forma de expresar esta estructura, la realización lingüística, sujeta a diferentes estilos según la lengua en la que estemos trabajando. Por lo tanto, las estrategias lingüísticas utilizadas en la redacción de estos textos deberán incluir tanto las funciones prototípicas como las diferencias de estilo entre una lengua y otra. Aquí radica su mayor interés como tema de estudio para los lingüistas y también su mayor dificultad.

Como segundo aspecto a tener en cuenta, aparte de las funciones retóricas, sobresale el componente interactivo que cada género promocional turístico encierra, basado en la función interpersonal descrita por Halliday (1985) y en la forma distinta de ser expresada, ya que existe un sustrato lingüístico y cultural que es decisivo para su objetivo final, la persuasión, y que varía según la lengua y el género (Suau Jiménez, 2005, 2010, 2011b; Labarta Postigo y Suau Jiménez, 2006; Suau Jiménez / Dolón Herrero, 2008; Mapelli, 2008; Vázquez y Giner, 2009). En otras palabras, la interpersonalidad, o forma en la cual el autor de un texto se relaciona con el lector, se manifiesta constreñida por variables lingüísticas y también genéricas. Por lo tanto, será necesario su estudio para identificar mecanismos, estructuras y marcadores propios de cada lengua, ya que es muy habitual que las web turísticas se traduzcan o que se parta de modelos en inglés para redactarlas en español o viceversa. Así como la estructura funcional retórica es homogénea y podemos hablar de funciones típicas que constituyen un género turístico, el patrón interpersonal varía de una lengua a otra. Si éste no se tiene en cuenta respecto a la lengua meta, al redactar o al traducir, el resultado será catastrófico ya que el lector no reconocerá estos mecanismos expresivos y, por lo tanto, el género no cumplirá bien con su objetivo de persuasión. Así pues, se necesita tener patrones por lenguas que describan los marcadores interpersonales, con objeto de diseñar estrategias lingüísticas adecuadas al objetivo último, la persuasión del lector.

\section{Géneros de promoción turística}

En primer lugar, partimos de la definición de género más conocida y aceptada, la que propone Swales (1990):

A class of communicative events, the members of which share some set of communicative purposes. These purposes are recognized by the expert members of the parent discourse community, and thereby 
constitute the rationale for the genre. This rationale shapes the schematic structure of the discourse and influences and constrains choice of content and style (1990: 58).

Es decir, los miembros de la comunidad discursiva en cuestión - aquí la turística - deben compartir el mismo objetivo comunicativo, que ha de ser reconocido por todos los miembros y formar así la base racional que moldeará la estructura esquemática del discurso e influirá sobre la elección del estilo y el contenido.

En segundo lugar, tomamos igualmente en consideración para esta argumentación teórica la clasificación y aproximación hecha por Calvi (2010) de los géneros turísticos:

[...] Es muy difícil que los géneros se presenten en estado puro; más bien, se combinan e interactúan entre ellos formando sistemas, colonias, cadenas, etc., con diferentes relaciones de interdependencia. El hibridismo, lejos de ser una condición excepcional, suele ser la norma; aunque existen, sin duda alguna, géneros con un grado elevado de convencionalismo [...] (2010: 16).

En otras palabras, los géneros turísticos son proclives a presentarse de forma híbrida. A esto habría que añadir la revisión teórica que hace Fairclough (2003) y que comparto, en cuanto a géneros comunicativos y géneros estratégicos, ya que se ajusta perfectamente al caso de los géneros de promoción que estoy tratando. Partiendo de la distinción que hace Habermas (1984) entre acción comunicativa y acción estratégica, es decir, interacción orientada a conseguir entendimiento frente a interacción destinada a conseguir resultados, Fairclough, (2003: 71-72) distingue géneros comunicativos de géneros estratégicos, apuntando a que estos últimos están más fuertemente dirigidos hacia la consecución de su objetivo que los comunicativos y presentan una estructura más predecible y estable. Es difícil hacer una clasificación absoluta de los géneros en estas dos categorías y habría que hablar, más que de una división dual, de un continuum o gradación de los mismos según la combinación de estos dos componentes. Sin embargo, las webs de promoción turística pueden tildarse de géneros estratégicos, ya que su sesgo es principalmente el de la persuasión, es decir, la consecución de un resultado o una acción por parte del receptor, en este caso, cliente. Esta revisión teórica sustenta nuestra postura respecto al género web de promoción turística, su predictabilidad y estabilidad independientemente de la lengua que estemos tratando.

Siguiendo con Calvi y su aproximación al género web de promoción turística, aunque en este caso, institucional, la autora sostiene que es un género fronterizo, que "[...] conjuga la fuerza promocional de los anuncios y de los folletos con una mayor riqueza informativa, propia de las guías, aprovechando también la flexibilidad y la interactividad del medio (imágenes, vídeos, buscadores, vínculos, etc.” (2010: 20), opiniones que compartimos.
Por lo tanto, la web de promoción turística se podría definir como género estratégico y fronterizo, dadas las características y la argumentación antes expuestas. Antes de entrar en la ejemplificación de funciones retóricas, diremos que éstas, según Swales (1990) y Bhatia (1993), que a su vez se basan en el funcionalismo de Halliday $(1978,1984)$ son las acciones verbales que conforman la estructura de un género, determinada ésta por su objetivo comunicativo. A través de las funciones se pueden identificar y reconocer los distintos géneros que una comunidad discursiva requiere para su comunicación. Ejemplos de funciones retóricas son la descripción, explicación, ejemplificación, citación, sugerencia, indicación, conclusión, recomendación, presentación, negociación, etc., diferenciándose según el género y la disciplina o dominio de especialidad del que se trate.

No existen grandes diferencias en el cómputo y tipo de funciones retóricas en las webs de promoción turística en inglés y español (Suau Jiménez, 2001; Suau Jiménez y Dolón Herrero, 2007). Una muestra de estas funciones en lengua española sería:

Descripción:

1. El aceite de oliva, cuyo cultivo se extiende en toda la provincia, es el principal protagonista de la cocina cordobesa.

2. La ciudad de Cádiz se sitúa en una península situada en una bahía. Esta forma peculiar de su costa, bañada por las aguas plateadas del Océano Atlántico ofrece una bellísima estampa que le ha ocasionado el sobrenombre de "la tacita de plata.

Ejemplificación y Explicación:

1. Podemos citar entre sus geniales recetas el salmorejo y el gazpacho, sopas frías de hortalizas, de gran valor nutritivo y delicioso sabor, especialmente en las cálidas estaciones del año.

2. La antigua "Gadir" (que significa "ciudad fortificada") fue fundada por los fenicios...

Indicación/Sugerencia:

1. Huelva no tiene aeropuerto por lo que los más cercanos son: El Aeropuerto de Sevilla (SVQ) y el Aeropuerto de Faro en Portugal (FAO). Aquí puede ver las distancias a los principales destinos de la Costa de la Luz en Huelva.

2. Con las playas de la provincia no tiene comunicación por tren, por lo que en este caso el autobús es la única alternativa, a parte del taxi o del vehículo propio.

Recomendación:

1. Valencia, la tierra de flores y fallas, es una de las ciudades más grandes e importantes de España, y una de las más vivas. Al estar situada a la orilla del mar Mediterráneo, uno se encuentra las playas en el mismo corazón de la ciudad. No sorprende que, sobre todo durante el verano, la visiten gran cantidad de turistas. Pues si uno quiere vacaciones en la playa con fantásticas posibilidades para practicar cualquier deporte y disfrutar de una vida nocturna rutilante, junto con una amplísima oferta cultural, entonces Valencia es el sitio para ello. 
Fuente:http://www.red2000.com/spain/1index.html

Si analizamos la realización lingüística de todas estas funciones, observamos características recurrentes tales como nominalizaciones (...es el principal protagonista de la cocina cordobesa / el autobús es la única alternativa...), personificaciones ("Huelva no tiene aeropuerto por lo que los más cercanos son) una cierta distancia conseguida a través de oraciones impersonales (“...uno (utilizado en formas coloquiales impersonales) se encuentra las playas en el mismo corazón de la ciudad I "...si uno quiere vacaciones en la playa con fantásticas posibilidades) y pocas oraciones en forma personal o con una alusión directa al receptor, a la vez que el uso de oraciones ponderativas con adjetivos calificativos de significado positivo (fantásticas posibilidades / vida nocturna rutilante / amplísima oferta cultural). Todo este entramado lingüístico obedece a un estilo propio en el uso del español, así como a un patrón interpersonal basado en un sustrato cultural también idiosincrático de la lengua española, que se da también en otros géneros - periodísticos de opinión, artículos de investigación - y en otras especialidades - finanzas, economía y empresa, ciencias - (Mur Dueñas, 2010; Vázquez y Giner, 2009; Suau Jiménez, 2011a) y es por lo tanto extrapolable aunque hacen falta más investigaciones que aporten nuevos datos y ayuden a definir el patrón o modelo.

Otra muestra similar en lengua inglesa sería esta:

Descripción:

1. "Britain is quite famous for its fish and chips, which is cod or haddock deep fried in batter and served with chips (fries)."

2. "Pub food varies in quality from fresh homemade produce to re-heated, mass produced menus.

3. Decent pub grub is extremely good value for money and some pubs offer meal deals such as two courses for $£ 5$ or children eat free.

Ejemplificación:

1. "A typical pub menu will offer a variety of choices such as fish and chips, lasagne, curry, shepherds pie, chicken pie, salads, pasta, jacket potatoes, steak and grill and baguettes and sandwiches."

Explicación:

1. "The law in England states that you have to be 18 years old in order to buy alcohol from a pub, off licence, supermarket or other outlet. If you look under 18 years of age then you will be asked for some ID with your date of birth on it. It is illegal to give alcohol to a child under the age of 5."

2. "Pubs operate in different ways when it comes to ordering but you usually choose a table which will have a number on it. You then decide what you want to order and place the order at the bar."

Indicación/Sugerencia:

1. "Staff from larger hotels are also recipients of tips. People who carry your luggage, doormen or concierge are usually given tips. For bell boys it may be a £1 but if a concierge is very helpful during your stay you may want to leave more.
2. "Apart from pubs and wine bars, you can buy alcohol in shops called off licences, supermarkets and some local shops. The cheapest option for buying alcohol is in supermarkets."

Recomendación:

1. "You can book either by visiting the restaurant in person or by telephone. All restaurants in the UK are now a non smoking area. If you are a smoker, you may want to enquire if there is anywhere to smoke after your meal." Fuente:http://www.tourist-information-uk.com/ guides/tourist-information-advice/eating-anddrinking/\#ixzz1dgL1LuOx

En este caso, la realización de las mismas funciones retóricas es distinta a la del español, no en cuanto al contenido proposicional estrictamente dicho o a los conceptos de mayor carga léxica, sino a otros elementos discursivos. Estos son las formas verbales directas (The law in England states that you have to be 18 years old...), la fortísima pronominalización (You then decide what you want to order...) que incluye al receptor acortando así la distancia con él/ella, la mitigación (If you are a smoker, you may want to enquire if.../ You can book either by visiting...), etc. No se utilizan tanto, sin embargo, las oraciones impersonales o las estructuras ponderativas a través de adjetivos calificativos.

Todas estas diferencias en el modo de realizarse las funciones retóricas conforman una función discursiva llamada metadiscurso interpersonal o interpersonalidad.

\section{El metadiscurso y la interpersonalidad}

El metadiscurso, como parte del discurso que ayuda al receptor del texto a organizar, interpretar y evaluar la información dada (Vande Kopple, 1985 y Crismore et al., 1993) es un concepto y a la vez una herramienta fundamental en el estudio de esta lengua de especialidad. El discurso turístico se podría comparar al concepto de constructo social (Fairclough, 1992, 1995), sugiriendo que los textos son parte de los acontecimientos sociales o la forma lingüística en la cual la gente actúa e interactúa socialmente. Tanto un autor como su audiencia son vistos como agentes sociales cuyas acciones no son libres, ya que están socialmente delimitadas o constreñidas. Por lo tanto, el metadiscurso es especialmente importante en ciertos géneros con un claro propósito performativo, como ocurre con los géneros de promoción de servicios u objetos turísticos -páginas web- cuyo propósito es que el turista/viajero no solo descodifique un mensaje, sino también que, como resultado, actúe, o sea, que consuma. Hyland (2005) sugiere que es una categoría funcional dentro del discurso, que no se puede dejar de tener en cuenta y que se realiza lingüísticamente a través de unas determinadas marcas, como son los matizadores, los marcadores de actitud, de compromiso, la auto-referencia, etc., a su vez realizados a través de verbos epistémicos, adverbios, verbos en imperativo, pronombres personales, ciertos adjetivos, etc. Hyland / Tse (2004) han propuesto un modelo o patrón metadiscursivo basado en el discurso académico, pero que 
constituye una base fiable para extrapolar al discurso turístico, como ya se ha demostrado (Suau Jiménez, 2005, 2010, 2011; Suau Jiménez / Dolón Herrero, 2008).

Aunque Hyland (1998) y Hyland / Tse (2004) incluyen en el metadiscurso tanto la variante textual como la interaccional o interpersonal, creemos, al igual que otros investigadores (Dafouz Milne, 2008; Vázquez / Giner, 2009) que la esencia del metadiscurso es la relación interpersonal y no la textual, ya que, por la propia definición del concepto, éste ha de tomar en consideración la subjetividad del emisor y del receptor, es decir, su aspecto cognitivo y su conocimiento del mundo, vehiculando todo ello a través de unas estrategias lingüísticas concretas basadas en el uso de marcadores específicos. Por ello, preferimos utilizar el término interpersonalidad, función ya acuñada (http://www.interlae.com/) y que describe mejor la parte del metadiscurso que nos interesa.

La interpersonalidad en el ámbito del turismo ha sido objeto de numerosos trabajos que han analizado y descrito diferencias importantes en el uso de estrategias lingüísticas a través de marcadores metadiscursivos, especialmente en español, inglés y alemán (Suau Jiménez, 2005, 2011; Labarta Postigo / Suau Jiménez, 2006; Mapelli, 2008). Se ha demostrado así que esta función, esencial para la persuasión, está fuertemente sesgada por factores tales como la lengua y el género.

\section{La interpersonalidad según lenguas y géneros}

Vamos a dar cuenta de diversos trabajos relacionados con las estrategias lingüísticas aplicadas a la redacción, traducción y confección de páginas web promocionales en el ámbito turístico. En mi trabajo dedicado a comparar usos interpersonales entre artículos de investigación y ciencia de divulgación en inglés (Suau Jiménez, 2005), comprobé que los marcadores están fuertemente determinados por los géneros. Aunque ambos géneros coinciden en unos marcadores comunes: matizadores, marcadores de actitud y auto-mención, la frecuencia de uso no es la misma, lo cual da como resultado un patrón interpersonal muy diferenciado en ambos géneros. Así, la ciencia de investigación y su género, el artículo de investigación, debido a su convención de expresar objetividad, hace un uso frecuente de matizadores y ocasional de los otros dos marcadores. La ciencia de divulgación lo hace, sin embargo, de modo contrario, introduciendo un importante sesgo subjetivo a través de los marcadores actitudinales y la auto-mención, ya que el género artículo de divulgación está cercano al entretenimiento y la atracción del lector a través de aspectos más emocionales.

En el trabajo dedicado a las páginas web promocionales de turismo en español y alemán (Labarta Postigo / Suau Jiménez, 2006:9), también se pudo comprobar que existen diferencias importantes entre estas dos lenguas. Mientras el uso de matizadores - verbos epistémicos (tratar, aconsejar, poder, etc): son claves para tratar de explicar lo que no se puede explicar con palabras" / "Aconsejamos al amigo lector que seleccione si opta por visitar todo un barrio, o..." / "Todo esto se puede complementar con la visita a la Ciudad de las Ciencias

es sólo algo más elevado en alemán que en español, sí existe una gran diferencia en cuanto al uso de los realzadores - adjetivos calificativos:

Llegar por una emocionante ruta al Santuario de la Balma en Zorita.." / "Conocer la serena belleza de los parques naturales del Prat de Cabanes..." / "...en el magnífico entorno natural del balneario de Montanejos" / "...las espectaculares huellas de los dinosaurios de Alpuente.(Labarta Postigo / Suau Jiménez, 2006:9)

Estos son más del doble en los textos alemanes que en los españoles. El uso de marcadores de compromiso pronombres personales de $2^{\mathrm{a}}$ persona -, abundante en el alemán (1,8 \%), es escaso en español: $(0,02 \%): “ \ldots$ no deje de tener en cuenta la Lonja de la Seda”/ "...al amigo lector que seleccione".

También la automención-pronombres personales de $1^{a}$ persona-es relativamente más utilizada en los textos escritos en alemán (proporcionalmente 10 veces más): "Aconsejamos al amigo lector que seleccione"/ "Vamos a sugerirles unos cuantos de los museos y monumentos...". Con este trabajo, se hace patente una diferencia importante según la lengua, ya que campo y género son aquí idénticos.

En otros estudios dedicados al discurso y a los géneros turísticos en inglés y español (Suau Jiménez, 2006, 2011; Suau Jiménez / Dolón Herrero, 2007) se ha podido comprobar también, al igual que indica Mapelli (2008), que ambas lenguas presentan diferencias notables en la función interpersonal, afectando directamente la construcción discursiva de páginas web de promoción turística. El uso de realzadores en forma de adjetivos calificativos atributos es un elemento esencial. De esta manera se potencian valores como lo histórico, lo tradicional, lo grandioso, etc. En inglés, sin embargo, hay un uso menor de realzadores y cuando estos se utilizan, los valores que se quieren transmitir al turista / viajero son lo espectacular, lo moderno, lo emocionante o lo único. Por otra parte, en español hay un uso bajísimo de marcadores de compromiso y de actitud, y bajo de auto-mención y mitigadores, marcadores que en inglés son los más utilizados para expresar la interpersonalidad. Esto indica que por debajo de la función interpersonal hay un sustrato cultural y lingüístico que no se puede obviar, que es necesario identificar en todos sus matices en cada lengua y que constituye la esencia de las estrategias lingüísticas necesarias en la promoción turística. 
Ejemplos reales de estrategias lingüísticas en webs de promoción turística y análisis comentado

\section{Inglés:}

1. Lest there be any confusion, Sheffield Park Garden is actually located in East Sussex. Right, now that's out of the way we can also tell you that the best time to come here is in spring - when you'll find the place awash with daffodils and bluebells. Spend a lazy Saturday strolling by the lake (there are four to choose from), accompanied by a soundtrack of twittering birds that flitter about in the nearby bushes. Whenever you come here, though, there's always something different to see. In autumn, for example, the fiery red and orange leaves are reflected in the glassy water of the central lakes- enthusiastic photographers snapping away from the interconnecting bridges. http:// www.enjoyengland.com/idea/Countryside/SheffieldPark-Garden.htm

2. For mid range prices but no shortcuts take tea with a view over London at the National Portrait Gallery, where you'll be served with cakes, scones and sandwiches a-plenty. If setting is what you're after, choose the Sharrow Bay Hotel in the Lake District where the stunning backdrop of Ullswater will compete with dainty finger sandwiches for your attention. http:// www.enjoyengland.com/Things-to-do/Food-and-drink/ Afternoon-tea.htm

3. Soak up the genius of Shakespeare and release your inner thespian with the World Shakespeare Festival, an unprecedented celebration of the much-loved Tudor playwright. Along with old favourites like King Lear and Julius Caesar, the festival will showcase a huge cast of new productions inspired by the works of Shakespeare. Once you've had your fill of comedies, tragedies, political thrillers and booed the likes of lago and Lady Macbeth, head away from the spotlights to immerse yourself in more Shakespeare. The British Museum will host Shakespeare: Staging the World, a major exhibition presented in collaboration with the Royal Shakespeare Company. Witness life as Shakespeare lived it, with drawings, maps, precious coins, armour and other weird and wonderful Tudor objects. http://www.enjoyengland.com/idea/Events/TheWorld-Shakespeare-Festival.htm

4. Cross the half a mile of water that separates the Isle of Wight from the mainland and you'll discover dinosaur footprints, traditional seaside resorts, world-renowned sailing villages, idyllic contryside and miles of stunning coastline. And it couldn't be easier to explore the island with over 500 miles of footpaths and plenty of award-winning beaches perfect for a cooling dip when the sun gets too hot. What do you get if you cross a dinosaur, a Roman villa and a monarch? Fascinating history, that's what. As you wander the island's coastline, you'll come across the footprints and fossilized remain of dinosaurs that roamed the island over 120 million years ago. See where Charles I was imprisoned at Carisbrooke Castle, soak up maritime heritage at Cowes and explore the Roman Villa at Brading. http://www.enjoyengland.com/Places-to-go/ Beaches-and-Coastline/Isle-of-Wight.htm

\section{Funciones retóricas:}

Las funciones retóricas, señaladas en cursiva en el primer texto, son básicamente Descripciones: it's actually located, that's out of the way, are reflected in y Explicaciones: the best time to come here is in spring, there's always something different to see. Sin embargo, estas funciones, en este caso descripciones (del comportamiento del futuro turista o viajero, de la situación o del servicio que se recibirá, de la belleza del lugar o sugerencias de actuación), realizadas en su mayoría a través de verbos en imperativo, están en negrita por coincidir con marcas de interpersonalidad (marcadores de compromiso, en los que se alude directamente al receptor): take tea, you'll be served, choose, soak up, release your inner..., Once you've had your fill of..., booed, head away from, immerse yourself, witness life, cross, you'll discover, What do you get if you cross a dinosaur, a Roman villa and a monarch?, you wander, you'll come across, soak up, explore.

\section{Interpersonalidad:}

Como se puede ver en los ejemplos, y hemos señalado más arriba, las marcas que forman la función interpersonal, estableciendo una conexión con el turista/viajero son principalmente marcadores de compromiso con utilizaciones del you/your o verbos en imperativo: spend, take tea, choose, y todos los mencionados en el párrafo anterior. Estas son características propias del metadiscurso interpersonal inglés, basadas en una relación directa y cercana con el receptor. Es importante resaltar el hecho de que coincidan funciones retóricas y función interpersonal, algo propio de géneros en los que se busca la influencia en el receptor y su acción o reacción. Hay ejemplos escasos de algún marcador de auto-mención: we can. También aparecen numerosos adjetivos calificativos (realzadores): stunning, dainty finger, huge, new, unprecedented, traditional, world-renowned, idyllic, perfect, award-winning, un rasgo también frecuente en el patrón metadiscursivo español (Suau Jiménez / Dolón Herrero, 2007; Mapelli, 2008), con lo cual se podría inferir que es una característica propia de los géneros de promoción turística, al margen de la lengua de uso.

\section{Español:}

1. El Festival Internacional Madrid en Danza se celebra en diferentes escenarios repartidos por la Comunidad de Madrid.

Se trata de un evento que reúne a un gran número de compañías de danza de todo el mundo englobando todos los estilos de baile, desde el clásico hasta la danza más vanguardista y con diversas propuestas nacionales e internacionales. La peculiaridad de este certamen es que incluye danza española y flamenco. El público 
puede disfrutar de las representaciones en los teatros y salas de Madrid y sus alrededores.

http://www.spain.info/es/vive/eventos/madrid/festival_ internacional_madrid_en_danza.html

2. La Rioja

¿Quién no conoce los vinos de la Rioja? Cuando llegues a esta zona estarás en la tierra del buen vino por excelencia, ya que sus caldos y sus extensos viñedos son famosos a nivel internacional. Para comprobarlo, puedes acercarte a la calle Laurel de Logroño (la capital), ir a las múltiples bodegas de la zona donde te ofrecerán un menú degustación, apuntarte a un curso de cata, a un viaje en el Vinobús... Otras recomendaciones culinarias en La Rioja son las verduras (especialmente famosas las de Calahorra) y recetas como las patatas a la riojana y las chuletillas al sarmiento. http:// www.spain.info/es/reportajes/la_gastronomia_el_plato_fuerte_del_camino_de_santiago.html

3. Valencia de Negocios

Valencia se ha convertido en un destacado centro de congresos en Europa y punto de encuentro de primer orden para quienes desean desarrollar sus negocios o participar en sus certámenes feriales. Instalaciones adecuadas para la celebración de todo tipo de congresos y reuniones profesionales, óptimas redes de comunicación que permiten un cómodo acceso a la ciudad, una variada oferta de alojamiento y una envidiable climatología todo el año, garantizan una estancia perfecta a quienes acuden a Valencia por motivos de trabajo. Todo ello en una ciudad cosmopolita donde se abre la posibilidad de compatibilizar la actividad profesional con el disfrute del tiempo libre, aprovechando el amplio abanico de ofertas culturales y gastronómicas.

El Palacio de Congresos de Valencia consolida esta oferta y convierte a la ciudad en lugar idóneo para la actividad comercial y el intercambio cultural. Este espacio combina perfectamente el diseño más audaz con las tecnologías y los equipamientos más modernos. Auditorios con todo tipo de instalaciones, salas de convenciones, restaurantes, cafeterías... Y en el exterior, $7.000 \mathrm{~m} 2$ de espacio verde con fuentes y estanques se convierten en zona ideal para el descanso y el esparcimiento.

Feria Valencia, pionera de las ferias de España, celebra más de cuarenta certámenes anuales a los que acuden unos 10.000 expositores de todo el mundo y más de un millón de visitantes. Su recinto ferial está dotado de una completa infraestructura para la celebración de congresos y convenciones. En el jardín del Turia, el Palau de la Música y Congresos de Valencia es un marco incomparable para la celebración de conferencias y exposiciones en pleno corazón de la ciudad.http://www. spain.info/es/ven/grandes-ciudades/valencia/valencia_ congresos_y_negocios.html

4. M.C. Escher. Universos Infinitos

Granada acoge alrededor de 135 de las mejores obras del artista holandés en dos sedes: el conjunto monumental de la Alhambra y el Generalife y el Parque de las Ciencias.

Escher es principalmente conocido por sus litografías y xilografías. En su obra se muestra una extraordinaria manipulación del espacio, el tiempo y la perspectiva, que reorganizó conforme a su personal e ingeniosa lógica. La exposición nos presenta su visión más científica, sobre todo matemática, en el Parque de las Ciencias. Por su parte, el conjunto de Alhambra alberga 25 obras que abarcan diferentes etapas de su producción artística. http://www.spain.info/es/vive/eventos/granada/exposicion_escher_universos_infinitos.html

\section{Funciones retóricas:}

En estos ejemplos, las funciones retóricas (básicamente Descripciones del servicio que recibirá el turista / viajero, de cómo se sentirá o de su comportamiento en el lugar de destino y Sugerencias de actuación) coinciden con las marcas de la interpersonalidad en los ejemplos 1 y 2 , al igual que ocurre con los ejemplos en inglés. Cada función, realizada a través de una expresión verbal, Se trata de un evento que reúne, La peculiaridad de este certamen es que reúne..., El público puede disfrutar..., ¿Quién no conoce..., Cuando llegues...estarás..., ...son famosos..., ...puedes acercarte..., apuntarte, ...te ofrecerán..., Otras recomendaciones...son las verduras..., responde a un tipo de marcador de interpersonalidad, que describimos a continuación. Es interesante resaltar este aspecto, sobre todo en el ejemplo 2 - más afín al patrón inglés de promoción turística - , ya que se entrecruzan las funciones retóricas y la función de la interpersonalidad, lo cual otorga al texto y al mensaje más fuerza, por recaer las marcas del metadiscurso interpersonal explícitamente en las acciones verbales y no en otros elementos de la oración como adjetivos, adverbios, etc. De esta manera, se consigue una relación más directa con el receptor o lector, y por lo tanto, una mayor carga de persuasión en el turista/viajero.

En los ejemplos 3 y 4 no se da, sin embargo, entrecruzamiento de funciones retóricas y función interpersonal. Aquí, por un lado están las funciones retóricas: se ha convertido, permiten, celebra, consolida, garantizan, nos presenta, etc. y por otro las marcas de interpersonalidad, que este caso son todas realzadores en forma de adjetivos calificativos.

\section{Interpersonalidad:}

Aunque hemos comentado el fenómeno por el cual se entrecruzan las funciones retóricas y la función de la interpersonalidad en estos ejemplos, dotando así al texto de una mayor fuerza de persuasión sobre el viajero/turista, observamos también, sobre todo en el ejemplo 1, 3 y 4, el uso de adjetivos calificativos (realzadores): gran número, todos los estilos, más vanguardista, diversas propuestas, peculiar(idad), destacados, óptima, envidiable, perfecta, cosmopolita, pionera, incomparable, idóneo, más audaz, extraordinaria, monumental, completa, ingeniosa, matemática, que transmiten unos valores al turista realzando el producto, en este caso, la Valencia de los Negocios o la Granada que 
alberga una exposición, muy en línea con investigaciones ya citadas (Suau Jiménez / Dolón Herrero, 2007; Mapelli ,2008). La estrategia promocional se basa aquí, pues, en la mencionada descripción del producto a través de unos valores concretos (la grandeza, la totalidad, la vanguardia, la diversidad, la pecularidad, la extensión, la fama, la multiplicidad). En el ejemplo 2, por el contrario, sí que se observa una cierta asimilación del patrón inglés, aspecto ya mencionado, al incluir pronombres de segunda persona (tú) como marcadores de compromiso, lo cual no es prototípico del modelo español hasta la fecha, pero puede indicar una tendencia hacia este modelo de promoción, que sin duda acerca el texto al turista/viajero 2.0 y es una forma de persuasión eficaz, ya que el receptor está directamente implicado en la acción que describe el texto.

\section{Conclusión}

En este artículo hemos intentado abordar las estrategias lingüísticas que nos encontramos en las webs de promoción turística en inglés y en español, especialmente en lo que se refiere al modo de expresar la función interpersonal y su entramado con las funciones retóricas típicas. Todo ello responde al objetivo de mostrar la importancia que tienen estas estrategias en la promoción turística dirigida al turista 2.0 , que cada vez actúa más como receptor directo de la misma, sin mediar otros agentes. Como decíamos en la Introducción, el turista o viajero 2.0 gestiona sus propios viajes y destinos, con lo cual el discurso de promoción turística ha de tener en cuenta las estrategias necesarias para su persuasión. El género web de promoción turística se compone en inglés y español de una batería de funciones retóricas más o menos similares, que son preceptivas y que conforman la estructura genérica necesaria. La función más importante es, por una parte, la Descripción, sea de situaciones, monumentos, eventos, rutas, alojamientos, comidas o bebidas y de cómo se sentirá el turista/viajero. La Descripción se realiza en el texto a través de verbos variados (ser, estar, situarse, etc.) y de adjetivos calificativos que transmiten valores (lo moderno, lo tradicional, lo excepcional, lo histórico, etc.) y es común al patrón inglés y español, aunque más utilizada en español, según investigaciones anteriores (Mapelli, 2008; Suau Jiménez, 2011b, 2011c) y según los ejemplos aquí analizados. Por otra parte y no menos importante está la Sugerencia de actuación, materializada por medio de verbos en imperativo o en condicional, sugiriendo o recomendando cómo se ha de comportar el turista/viajero si quiere sacar el máximo provecho a su viaje o estancia. Esta función es más típica del discurso promocional inglés, más directo con el receptor. Sin embargo, los ejemplos en español ya presentan también esta función, aunque en menor grado.

Estas funciones retóricas presentan a veces solapamiento con la función interpersonal o modo de relacionarse el autor con el lector o turista / viajero 2.0. En esos casos, las acciones verbales (verbos descriptivos) que fundamentan las funciones retóricas de Sugerencia de
Actuación y la función interpersonal, con marcadores de compromiso (pronombres personales de segunda persona e imperativos) son una misma cosa, lo cual sin duda refuerza el mensaje promocional turístico y atrae más al receptor al implicarlo en la acción misma. Este aspecto del solapamiento de funciones retóricas y función interpersonal, no estudiado anteriormente, es sin duda un hallazgo del presente trabajo, lo cual ahonda en el conocimiento del discurso de promoción turístico, y en particular en el análisis del discurso de las webs, aunque hacen falta investigaciones más extensas para corroborar o no este hecho.

En los casos en que las funciones retóricas de Descripción van separadas de la función interpersonal, ésta se materializa de forma importante - aparte de los verbos típicamente descriptivos como ser, estar, etc.- a través de realzadores - adjetivos calificativos - . Aquí se aprecia una ligera preponderancia del uso de los realzadores en español, aunque el discurso turístico inglés también los incorpora. De esta manera se transmiten unos valores que el sustrato de cada lengua y el objetivo turístico y comercial considera adecuados (lo nuevo, lo espectacular, lo moderno, lo único, lo histórico, lo tradicional, lo grandioso), sin duda fundamentales en el discurso turístico (Mape1li, 2008; Suau Jiménez, 2011b, 2011c). Como menciona Fairclough (1992), el emisor se sitúa así fuera de su propio discurso para controlar y manipular el propósito comunicativo: la persuasión, a través de estos valores.

Se dan otros marcadores importantes en inglés frente al español, como son los marcadores de compromiso. En los ejemplos analizados en el presente trabajo, observamos cómo el patrón inglés - abundante en marcadores de compromiso - parece influir en el discurso promocional español, propiciando así una relación directa con el receptor a través de pronombre personales o verbos en imperativo en segunda persona que hacen que el turista/viajero 2.0 se sienta integrado en lo que se le está transmitiendo. La frecuencia de uso de estos marcadores interpersonales se muestra como más prototípica de los géneros de promoción turística que de otros géneros como los económico-empresariales, los periodísticos o los científicos, según trabajos de diversos autores (Hyland / Tse, 2004; Suau Jiménez I Dolón Herrero, 2007, Suau Jiménez 2011b, 2001c).

Podríamos concluir que existen, pues, unas tendencias lingüísticas o estrategias prototípicas diferenciadas en el discurso promocional inglés y español: la descripción y los realzadores en español, la sugerencia de actuación y los marcadores de compromiso en inglés. Sin embargo, también existe una cierta zona de uso común de las dos lenguas y sus patrones, en el sentido que hemos indicado. Por último, el hecho del solapamiento, en ocasiones, de estas funciones retóricas con la función interpersonal, fenómeno no observado anteriormente, se revela como un aspecto nuevo que hay que tener en cuenta en el discurso promocional en las webs, que habrá que seguir estudiando. Es evidente, pues, la necesidad de tener en cuenta este entramado discursivo del lenguaje turístico promocional, con objeto de identificar tanto las funciones retóricas propias de los géneros de promoción como la interpersonalidad y 
sus marcas en inglés y español y aplicarlo a la redacción y a la traducción de las webs turísticas con garantías de rigor. Solo de este modo se podrá conseguir el propósito genérico de informar y persuadir al turista/viajero 2.0 para que elija sus destinos, viajes y hoteles según los objetivos de la entidad turística que diseñe cada web en concreto.

\section{Bibliografia}

Alesón Carbonell, María Amparo

2000 "Tourism: the problems of the definition of a new ESP. A study of the didactic implications of this characterization". En F. Luttikhuizen (Ed.) III Congrés Internacional sobreLlengües per a Finalitats Especifiques. Barcelona: Publicacions de la Universitat de Barcelona: 11-15.

Alcaraz Varó, Enrique / Hugues, Brian / Campos Pardillo, Miguel Ángel / Pina Medina, Víctor Manuel / Alesón Carbonell, M.A.

2000 Diccionario de Términos de Turismo y de Ocio. Barcelona: Ariel

Alcaraz Varó, Enrique / Martínez, José Mateo / Yus Ramos, Francisco (Eds.)

2007 Las lenguas profesionales y académicas. Barcelona.

Bhatia, Vijay

1993 Analysing genre: Language use in professional settings. London: Longman

Brieger, Norman

1997 Teaching business English Handbook. York: York Associates Publications: Ariel.

Calvi, Maria Vittoria

2006 Lengua y comunicación en el español del turismo. Madrid: Arco Libros.

Calvi, María Vittoria

2010 "Los géneros discursivos en la lengua del turismo: una propuesta de clasificación”, Ibérica 19, 9-32.

Cerdá Redondo, Enriqueta

2000 "English teaching for tourism studies: A methodological approach". En Actas del X Congreso LusoEspanhol de Linguas Aplicadas às Ciencias e às Tecnologías (pp.4-11).Portalegre: Instituto Politecnico de Portalegre, Portugal.

Collin, Peter

1994 Dictionary of Hotels, Tourism and Catering Management. Teddington: Peter Collin Publishing.

Crismore, Avon / Markkannen, Raija / Steffensen, Margaret

1993 "Metadiscourse in persuasive writing: A study of texts written by American and Finnish university students". Written Communication,10 (1), 39-71.

Dafouz Milne, Emma

2008 "The pragmatic role of textual and interpersonal metadiscourse markers in the construction and attainment of persuasion: a cross-linguistic study of newspaper discourse”. Journal of Pragmatics, 40 (1), 95-113.

Fairclough, Norman

1992 Discourse and Social Change. Cambridge: Polity Press.
Fairclough, Norman

2003 Analysing Research. Discourse: Textual Analysis for Social. London: Routledge.

González García, Virginia

2011 "El discurso del turismo en internet: hacia una caracterización de sus géneros". En: Sanmartín, Julia (Ed.) (en prensa) Discurso Turístico e Internet. Madrid: Iberoamericana/Vervuert, Lingüística Iberoamericana Vol. 48, pp.13-50.

Halliday, Michael A.K.

1978 Language as Social Semiotics. London: EdwardArnold.

Halliday, Michael A.K.

1985 An Introduction to Functional Grammar. London: Edward Arnold.

Hyland, Kenneth / TSE, Polly

2004 "Metadiscourse in Academic Writing: A Reappraisal". Applied Linguistics 25/2, 156-177.

Hyland, Kenneth

1998 Hedging in Scientific Research Articles. Amsterdam: John Benjamins.

Hyland, Kenneth

2005 Metadiscourse: Exploring interaction in writing. London: Continuum.

Labarta Postigo, María / Suau Jiménez, Francisca

2006 "Análisis del metadiscurso en textos especializados turísticos: los matizadores discursivos y la pronominalización en alemán y español”. CONGRESO ALED, Valparaíso, Chile.

Mapelli, Giovanna

2008 Las marcas de metadiscurso interpersonal de la sección turismo de los sitios web de los ayuntamientos. En Calvi, MariaVittoria, Mapelli, Giovanna y Santos López, Javier (Eds.), Lingue, culture, economia: comunicazione e pratiche discorsive, Milano, FrancoAngeli, 173-190.

Mur Dueñas, Pilar

2010 "Attitude markers in business management research articles: a cross-cultural corpus-driven approach". International Journal of Applied Linguistics, 20, 1, 50-72.

Pickett, Douglas

1989 "The sleeping giant: Investigations in Business English”. En Language International, vol.1(1): 5-1

Sanmartín, Julia (Ed.)

2011. Discurso turístico e Internet. Lingüística Iberoamericana, Vol. 48. Madrid: Iberoamericana/Vervuert.

Suau Jiménez, Francisca

2001 "El género y el registro en la traducción del discurso profesional: un enfoque funcional aplicable a cualquier lengua de especialidad". Culturele <http://www.ub.es/ filhis/culturele/tinasuau.html>

Suau Jiménez, Francisca / Dolón Herrero, Rosana

2007 "The Importance of Metadiscourse in the genre 'Promotion of Touristic Services and Products': Differences in English and Spanish". En Galová, Dita (Ed.) Languages for Specific Purposes: Searching for Common Solutions. Cambridge Scholars Publishings, pp.71-79. 
Suau Jiménez, Francisca

2011c "El metadiscurso interpersonal en los subgéneros periodísticos de opinión en inglés y español. Aplicación didáctica a la traducción”. En Gómez Molina, José Ramón; Carbonell Olivares, María y Estévez Fuertes, Nicolás (Eds.) El reto de la comunicación escrita en el Siglo XXI. QUADERNS DE FILOLOGIA. Publicacions de la Universitat de València (PUV), pp. 249-268.

Suau Jiménez, Francisca

2011b "Páginas web institucionales de promoción turística: el uso metadiscursivo interpersonal en inglés y español”. En Sanmartín, Julia (Ed.) Discurso turístico e Internet, Madrid: Iberoamericana/Vervuert, pp. 125154.

Suau Jiménez, Francisca

2011a "La persuasión a través del metadiscurso interpersonal en el género Página Web Institucional de Promoción Turística en inglés y español”. En Calvi, Maria Vittoria y Mapelli, Giovanna (Eds.) La lengua del turismo: Géneros discursivos y terminología. Bern: Peter Lang, Colección: Linguistic Insights, Vol. 138, pp. 177-200.

Swales, John

1990 Genre Analysis: English in Academic and Research Settings. Cambridge: CUP

Vande Kopple, William J.

1985 "Some exploratory discourse on metadiscourse". College Composition and Communication 36, 82-93.

Vázquez, Ignacio / Giner, Diana

2009 "Writing with conviction: The use of boosters in modeling persuasion in academic discourses". Revista Alicantina de Estudios Ingleses 22, 219-23.

\section{Notas}

1 Este trabajo es parte de la investigación relativa al Proyecto de Investigación Ref. FFI2011-2471 concedido por el Ministerio de Ciencia e Innovación de España, "Análisis léxico y discursivo de corpus paralelos y comparables (español-inglésfrancés) de páginas electrónicas de promoción turística”.

Recibido:

Reenviado: Aceptado:
$29 / 12 / 2011$

$1 / 3 / 2012$

$10 / 3 / 2012$

Sometido a evaluación por pares anónimos 